\title{
Habits of Mind in an Uncertain Information World
}

The current political and cultural polarization in the United States and other countries has significant implications for all educational institutions and for libraries and librarians. The interrelated issues of trust, credibility, and authority now present major challenges because of the uncertainty of the social media environment, competing information "bubbles," and enduring cognitive biases. The accelerating fragmentation of the media and information ecosystems undermines communal understanding of large and complex issues that citizens must face. To address this profound societal challenge, academic librarians should collaborate with faculty members to create communities of inquiry for students—sustained "high impact practices" that address the complexity of the current information environment. This article shows one model for using the Framework for Information Literacy for Higher Education to create learning goals for a range of in-depth learning experiences that cultivate habits of mind essential to discernment in the current political and cultural climate.
No matter how large the tissue of falsehood that an experienced liar has to offer, it will never be large enough... to cover the immensity of factuality.

\section{— Hannah Arendt}

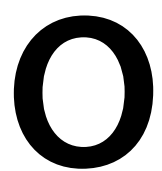
urs is a fraught time. We see blaring headlines about stolen elections, the questioning of scientific findings and of the scientific method itself, of mutual incomprehension across political and cultural divides, of accepted norms upended, of governing processes questioned, and of facts themselves-facts comporting with reality-doubted. The swirling cacophony of competing viewpoints, perspectives, agendas, and "facts," accelerated by a saturating and saturated media environment, challenges anyone seeking a firm ground for reasoned debate, reflection, and discussion-and anyone commited to teaching and scholarship. As a profession with ancient and honorable roots, including exposing

\section{Craig Gibson and Trudi E. Jacobson}

Craig Gibson (gibson.721@osu .edu) is Professor and Professional Development Coordinator at The Ohio State University, Columbus, Ohio.Trudi E. Jacobson(tjacobson@ albany.edu) is Distinguished Librarian and Head, Information Literacy Department at the University at Albany, SUNY, Albany New York.

Reference \& User Services Quarterly, vol. 57, no. 3, pp. 183-92 (c) 2018 American Library Association. All rights reserved.

Permission granted to reproduce for nonprofit, educational use. 


\section{FEATURE}

uncomfortable truths, teaching requires a ground of reliable factuality, a foundation for debate, discussion, and improvement, no matter the level of education, the subject, or the method of instruction.

The library community is deeply involved in the educational enterprise, whether all of its members believe or not in a strict "teaching role" for themselves. Libraries of all types perform an essential educational role-providing collections and services for faculty, students, and larger academic communities in the case of academic libraries, and in public libraries, providing a broader array of collections, services, and programs for citizens of all ages in communities. Special libraries of all types provide essential services, sometimes in a more narrow instrumental way, for their clienteles. No matter the group served, libraries collect or provide access to information resources - scholarship, archives, data, primary sources, artifacts, popular press materials-that perform an educational role. And librarians themselves participate in expanding public or community understanding of these resources through a range of teaching programs and expert consultation and advising roles.

We are now faced with foundational questions about how libraries, as educational entities concerned with learning, investigation, scholarship, and reflection, should function in a time of questioning facts and truth itself. The larger society and the citizenry of the United States, and of other countries, are subject to constant, accelerating social media storms and divisive debate everywhere that cause great uncertainty in the public mind about what can be believed and be accepted as reasonable in the public sphere on matters of great public concern: whether climate change is real, whether childhood vaccinations cause autism, whether lowered tax rates will create booming economies and more jobs, whether antiimmigration measures are needed to protect national identities, or whether the addiction and opioid crises in developed countries can be "cured" through traditional treatments. The intersecting complexities of many of these debates create even more uncertainty in the minds of many. While scholars and scientists offer sound evidence to the general public that climate change is real, that childhood vaccinations are necessary and do not cause autism, and that lowering tax rates does not necessarily produce more jobs and prosperity, so much doubt and uncertainty about the role of scholarship, science, and even reasonable observation of reality has been created that many "facts" and "explanations" count equally for some people. There is assuredly a spectrum of doubt across many of these contested issues, but we live in a prevailing climate of uncertainty and unsettledness about facts and grounded truth that comports with reality. Politicians, media organizations, think tanks, and public figures of all levels of knowledge and sophistication disagree among themselves, espouse sharply polarized views, and are committed to preconceived sets of facts grounded in divergent value systems. The common ground for debate, dialogue, and ongoing discussion is missing-a public realm where some information and facts are agreed on as a basis for a search for truth. Because this larger common ground is missing, libraries' educational role itself has become more uncertain.

\section{SIGNS OF THE TIMES}

Evidence abounds of the sharply accelerated polarization about factuality itself and the resulting uncertainty:

- There is increasing polarization between more and less highly educated adults in the United States, according to the Pew Research Center-across positions on specific policy issues as well as across ideological and generational lines. ${ }^{1}$

- In the media environment, according to the Berkman Klein Center for Internet and Society, there is asymmetric polarization between left- and right-leaning media outlets, with conservative perspectives more aligned with highly partisan and less traditional media organizations and outlets, and liberal perspectives more aligned with traditional "mainstream" journalistic practices and media organizations (which may have their own ideological perspectives, of course). ${ }^{2}$

- In civic education, one study conducted by the Stanford History Education Group found that high-school students are easily misled by information resources they found on the Internet-resources focused on public policy issues. Uncertainty about how to judge the credibility of resources and the facts within them-with resulting doubt and polarization - may be rooted in deficits in our educational system. ${ }^{3}$

- One notable educator and educational technologist, Mike Caulfield, has developed an innovative online project, Digital Polarization Initiative, or DigiPo, sponsored by the American Association of State Colleges and Universities (AASCU), to teach students strategies for assessing the credibility of sites on the Internet. His initiative in developing this course is one educational response that teaches students skepticism, critical thinking, contextualization of information, and habits of mind for effective civic literacy. ${ }^{4}$

\section{THE MACRO TRENDS AGAINST TRUST}

These "signs of the times" point to larger cultural trends in our society with intensely local implications for libraries and for those they serve and attempt to educate. At the same time, some of these trends are global in reach and impact. The issues of trust and credibility pervade our daily lives when using any information source, from whatever place of origin. We are ever more aware of the challenges in making decisions about what to believe, which result from the separate and parallel universes of discourse and belief that are available to us. Researchers increasingly identify intractable cognitive biases, prejudices, and close-mindedness as 
barriers to informed decision-making. The media environment exacerbates tendencies toward confirmation bias and motivated reasoning identified by psychologists as handicaps in seeking common meaning, and a reliable set of facts, across large groups of people. The race for attention in the social media world, and the fracturing of attention itself, make critical reflection and questioning hugely problematic for most. Our political debates reflect this instability, uncertainty, and lack of context and perspective; isolated, fragmented facts or constructed narratives developed by highly partisan groups mark our landscape. The cacophony of competing voices drowns out time for focused reflection, and many citizens tune out the noise or select one source or channel that they can trust. The college classroom and the library that is its extension are inevitably affected by the uncertainty about facts, the polarized discourse, and the questioning of the basis for knowledge itself, as well as the methods for the search for truth. Before continuing with the examination of larger trends that diminish trust, it is worth defining important concepts used in this section.

\section{COMMON MEANING}

In a period dubbed the "post-truth" era, in which the actual meanings of words and phrases are being obfuscated to propel particular views (consider the use of fake news to label factual news that one does not agree with), it is important to define one's terms: trust, credibility, authority, and expertise. It is thought provoking to realize that while the meanings of these words are commonly understood, social and political impacts may have fragmented the universal concepts behind the words. (Post-truth itself was designated the 2016 word of the year by Oxford Dictionaries; it means "relating to or denoting circumstances in which objective facts are less influential in shaping public opinion than appeals to emotion and personal belief.")

In defining what trust is at the most basic level, Brad Love, Michael Mackert, and Kami Silk capture, from the work of others, key observations about the characteristics of trust and the difficulty, such as we now face, of communicating when trust is lacking. Citing a 2008 article by Nick Allum et al., they write, "This essential role of trust—defined as a willingness to depend-meshes with findings that the public's understanding of complex issues does not always result from data-driven understandings of experts in government, media, or industry."

They continue: "A lack of a trusting relationship adds significant complexity to any communication transaction because it acts as a barrier between parties. . . . Reduced willingness to depend on supplied information creates a gulf between professional assessment and public comprehension." ${ }^{16}$ This absence of trust, or unwillingness to depend on the information provided by an individual, stems in part from a lack of credibility, which is itself defined by Shawn Tseng and B. J. Fogg in most cases as, simply, believability.
They note that "credibility is a perceived quality; it doesn't reside in an object, a person, or a piece of information." Determining credibility involves evaluating trustworthiness and expertise. ${ }^{8}$ This leads to examining the meaning of expertise, which is defined by the third edition of the Oxford English Dictionary (OED) as "the quality or state of being expert; skill or expertness in a particular branch of study or sport." The pertinent meaning of authority, also from the OED, is "the fact or state of possessing credible information; power to inspire belief in the truth of something; right to be believed; testimony, evidence."

Much of the time, trust is engendered by the credibility, or believability, of an authority. Expertise may play a role in that credibility, and certainly expertise has been taught as a marker of authority and credibility. Yet, as will be described later in this section, expertise itself is under assault, and, as with credibility, authority is a perceived quality-and one that has been profoundly affected by the parallel and separate universes of belief.

The current accelerating political polarization and the questioning of information and facts comes at the end of several decades of the splintering and fracturing of discourses and of the information landscape itself. Trust depends on belief in the credibility of experts and authoritative sources and a willingness to grant them provisional assent in determining a course or action or a way of thinking about the world. This attitude of trust-a habit of mind in itself-has diminished through the fracturing of discourses and the baneful effects of a media-saturated polarization. A memorable term, borrowed from philosophy and used by Julian Sanchez of the libertarian think tank Cato Institute, is epistemic closure, 9 by which Sanchez means the tendency of many of his fellow conservatives to accept only information and perspectives from within the conservative camp and the premature closing off of dialogue and information seeking from beyond the perspectives within that circle. For Sanchez, the construction of a separate, filtered media bubble with only conservative voices and the exiling of heretics who question the "trusted" voices within that bubble fatally compromise the search for meaning and truth in a democratic society. While epistemic closure may not become a term widely used even in academic circles, the idea underpinning Sanchez's use of it distills in a crucial way our societal-and educational-challenge. The closing off of alternative perspectives, information sources, data, and voices from one's own personal information landscape results in an attenuated and impoverished capacity to reflect and to learn.

Sanchez used the term epistemic closure at a particular moment in time, when conservative media had developed and matured and were increasingly hostile to mainstream media's presentations of facts. His notion of epistemic closure as a construct for intellectual cocooning anticipated soon afterward the publication of Eli Pariser's The Filter Bubble..$^{10}$ This study of how algorithms in Facebook and Google create isolated communities and individuals who always see and read the same information has focused sustained attention 


\section{FEATURE}

on the consequences of social media and its potentially divisive effects. While some recent studies have qualified some of the suggested results of the "filter bubble"-notably in finding that different age groups have different media consumption habits, with traditional media such as cable television still exerting a powerful influence ${ }^{11}$ —many thinkers and researchers still see the isolating and segregating effects of algorithms used by social media as harmful to creating common understandings about facts in our society. The implications of the filter bubble are, along with other causes, accelerating the political and culture divide in our society. The polarization of discourse resulting from epistemic closure as described by Sanchez-the self-isolation among media and intellectual elites and those who read and view them-is now greatly exacerbated by the filtering accomplished by algorithms in social media environments. So great is the concern about the lowering of intellectual discourse and the possibilities for making informed individual or collective decisions that a spate of other recent books are calling into question the very business model of social media companies_-advertising and addictive "clickbait" features_ that diminish even further the algorithm-driven results that searchers find..$^{12}$

The darkening of social media environments has reached a recent nadir in the US presidential election of 2016, with the US intelligence agencies' documented findings of the interventions by Russia via automated trolls and bots on Facebook and Twitter to influence the outcome in favor of one presidential candidate. These recent events greatly amplify trust problems regarding the information environments used by millions of people, and the continued debate about the precise impact of this social media intervention by a hostile power reveals, in itself, how the grounds for debating truth have shifted: experts in intelligence and the uses to which social media are put by hostile agents are now themselves questioned.

A recent book, The Death of Expertise: The Campaign against Established Knowledge and Why It Matters, captures some of the current challenges for a democratic society in which experts and expertise itself are now questioned. ${ }^{13}$ The many-layered difficulties for non-experts in deciding whom to trust about extraordinarily complex policy matters is made more challenging because experts themselves often disagree, because experts themselves have often been wrong, because experts cannot explain the nuances of complicated issues in accessible language to lay audiences or readers, because of a long-lasting strand of anti-intellectualism in American society, and because the digital information ecosystem has enabled the spread of "fake expertise" and made it possible for many nonexperts to promote their "research" or perspectives equivalent to those of scholars and researchers who have spent decades conducting studies according to the established rigors of scholarly methods. The easy conflation of "expert" with "elitist" in the public mind signifies further difficulty-a cultural reaction among many against those with knowledge, filtering out the perspectives of experts through the epistemic closure of one's group, one's tribe, one's own bubble of information sources. The reality that experts are themselves fallible and capable of error is reported in parts of the media environment to validate a false egalitarianism. The author of this book, Tom Nichols, does not offer easy solutions but does suggest that experts themselves adopt great humility and self-correction, and that they enforce greater accountability among themselves. He also identifies a greater role for public intellectuals, who can explain the more complicated policy issues to a larger public in ways that academic experts who write in technical language cannot.

Within academia itself-the arena for the greatest specialization and expertise in our society-a current debate about "reproducibility of results" is raging. This internal debate within higher education, particularly focused on the scientific and medical fields, adds to the increasing skepticism about expertise and authority among the general public. The myriad facets of a very complex set of issues relating to reproducibility of research findings-including research design, data collection and integrity, the value of "null" results, and the bias of scholarly journals for certain kinds of studies-are not well understood even in the academy. For the larger public, such notices of scientists' and experts' inability to replicate research results, or disagreeing among themselves about their findings, or very infrequently commtting outright data fraud further diminish trust in the scientific and research enterprise-the preeminent domain of expertise and experts. Furthermore, experts' inability to explain to the larger public the value of their research and the complexities inherent in their methods exacerbates the skepticism and reinforces "folk wisdom" about the perspectives of nonexperts and stereotypes about experts as arrogant, impractical, and out of touch. The reproducibility crisis is one symptom of a larger crisis of credibilitity and of the authority of experts themselves. ${ }^{14}$

The assault on experts and the habits of mind that they display is another feature of the larger fracturing of public discourse and the ways of discussing and debating matters of great public interest. The fragmented information ecosystem mirrors this larger fracturing-experts can be found across this ecosystem, but there is often mutual incomprehension among the groups who listen to different experts. The larger public often sees a false equivalence between groups of experts because of their own self-interest and their need to validate their own assumptions and values. The tribalism of our times, weaponized by competing media environments, exacerbated by the geographical segregation of those with different political viewpoints and cultural perspectives, and propelled by extreme individualism, has produced what Yuval Levin has called the "fractured republic." A moderate conservative, Levin sees the loss of cohesion in society primarily in terms of values and identity rather than in terms of a fragmented information ecosystem or in terms of cognitive biases. He looks to mediating institutions-in communities, families, religious groups, and nonprofit organizations-to 
create bonds that create greater coherence and possibilities for shared discussion and conversation. The role of information, scholarship, and expertise within these "mediating institutions" is not addressed in his book; the tendency of such groups to reinforce beliefs already held, rather than seeking different perspectives or other evidence, suggests that crosscutting mediating institutions may be needed to force many out of their own bubbles of information..$^{15}$ But the fracturing that Levin analyzes in the political and cultural sphere is another lens through which to examine our current challenges for teaching better habits of mind-in colleges and universities, or elsewhere. Creating new kinds of communities of inquiry where such habits of mind can be fostered on a sustained basis is one possible avenue for overcoming the forces of polarization and tribalism that militate against the critical thinking and self-teaching needed to trust experts and assess the information environment appropriately.

This filtering of information to confirm one's own intellectual preferences and search habits is, of course, based on much deeper cognitive biases and older human blind spots; the information and media environments have only exacerbated these tendencies. Daniel Kahneman's Thinking Fast and Slow, a recent best-selling explication of fallacies and cognitive biases, identifies numerous examples of errors in reasoning and decision-making. ${ }^{16}$ Two of the best-known errors, confirmation bias and motivated reasoning, figure most prominently in working against the individual assessment of information sources. The individual who engages in confirmation bias actively seeks information to validate or confirm what he already believes; when this tendency is reinforced by tribalism, polarization becomes rampant. Motivated reasoning is a complementary tendency to scrutinize evidence with greater skepticism if it does not fit one's existing beliefs or values. These individual blind spots create great difficulties for teachers at all levels who must inculcate habits of mind that make possible reasoned debate and discussion with others, the questioning of one's own assumptions and information-seeking preferences, and the default bubbles of individually trusted information sources. Cognitive biases at the individual level complicate the technological, cultural, social, and political challenges for critically reflective learners-those who can self-correct and join communities of learning that build up trust about expertise, scholarship, and the process of learning itself.

\section{OPPORTUNITIES FOR TRANSFORMATIVE LEARNING THROUGH COMMUNITIES OF INQUIRY}

Examining the myriad strains acting on the intersection of information, trust, and authority makes evident the need for librarians to engage students in rich learning situations that move significantly beyond mechanistic means of information evaluation, such as checklists. Designing learning opportunities with the goal of challenging students' sense of themselves demands a shift in thinking and practice. It requires educators who not only value the outcome but who also prioritize it in order to accomplish significant results:

By engaging in a learning process that is not merely informative but transformative, students have the opportunity to practice these life skills thoughtfully and consciously. While they are arriving at new understandings, they are also becoming aware of the process of transformation itself, thus being positioned to recognize and welcome opportunities for development later in their lives. This prepares them for lifelong learning and to think purposefully about what they should do and why they should do it. Learning that is transformative is characterized by a deep and enduring change in thinking that is evidenced through changed ways of being in the world. ${ }^{17}$

To strive for these results, the learning environment must be designed thoughtfully so that communities of inquiry are formed-communities in which critical reflection is regularly practiced and valued. In such courses and activities, content becomes a springboard for inquiry, which may then lead to transformation:

Transformative learning is learning that transforms problematic frames of reference-sets of fixed assumptions and expectations (habits of mind, meaning perspectives, mind-sets) — to make them more inclusive, discriminating, open, reflective, and emotionally able to change. ${ }^{18}$

This section delves into common curricular and cocurricular opportunities that might serve as appropriate venues that support learning about authority, expertise, and credibility in an atmosphere in which open discourse is valued. It is important that librarians and disciplinary faculty work together closely in such efforts. While one-time teaching sessions might provide an opportunity to begin a conversation about these issues, it is far from sufficient to address the habits of mind that will allow learners to work against confirmation bias, motivated reasoning, and other biases detrimental to true inquiry and reasoned use of information. This requires high-impact learning, as described by George D. Kuh, which leads students to see themselves and the world in a new way through contact with different perspectives and different worldviews. ${ }^{19}$

Matthew Wawrzynski and Roger Baldwin note two "strategies [that] are instrumental in promoting deep and transformative learning."20 Jack Mezirow claims that discourse helps to promote transformative learning. ${ }^{21}$ Structured and informal discussions and conversations assessing experiences, beliefs, feelings, and values among students and various members of the campus community can promote thoughtful reexamination of frames of reference and can lead learners to a more accurate and compelling understanding of the world 


\section{FEATURE}

one inhabits. Similarly, careful reflection can help students question long-held beliefs and unexamined assumptions in light of new experiences and alternative viewpoints that may enrich their comprehension of complex issues. ${ }^{22}$

Transformative learning can be fueled by high-impact practices, learning opportunities that "have significant effects on students' ethical awareness, challenging learners to confront alternative beliefs and values, and to think more deeply about their own." ${ }^{23}$ High-impact approaches involve "integrating ideas and diverse perspectives, discussing ideas with faculty and peers outside of class, analyzing and synthesizing ideas, applying theories, judging the value of information as well as one's own views, and trying to understand others' perspectives." ${ }^{24}$ Kuh catalogs a number of high-impact educational practices, including courses, assignments, and co-curricular activities that have been shown to increase student success. ${ }^{25}$

Each of the following categories of high-impact courses, programs, and initiatives has its own possibilities in regard to learning design and types of learners. The list is not exhaustive: additional opportunities that allow for discourse and self-reflection are likely to be found on individual campuses.

\section{Inquiry-Based Courses}

Courses with a significant emphasis on inquiry may be found across disciplines and within first-year requirements. These courses may meet general-education competencies such as critical thinking and writing. When inquiry serves as the underpinning for course content, it also promotes related habits of mind.

An example of this type of course, found at most academic institutions, is the Writing and Critical Inquiry seminar required of all students at the University at Albany. The description emphasizes the role that inquiry plays:

Based on established principles of rhetorical theory, Writing and Critical Inquiry provides students opportunities for sustained practice in writing so that students gain a deeper understanding of writing as a mode of inquiry and develop their ability to negotiate varied writing and reading tasks in different academic and non-academic contexts. Through rigorous assignments that emphasize analysis and argument, students learn to engage in writing as an integral part of critical inquiry in college-level study, become familiar with the conventions of academic discourse, and sharpen their skills as researchers, while improving their command of the mechanics of prose composition. Writing and Critical Inquiry also helps students develop competence in the uses of digital technologies as an essential 21 st century skill for inquiry and communication. ${ }^{26}$

\section{First-Year Seminars}

First-year seminars frequently serve to introduce new students to college, to a discipline, and to other students, in order to acclimatize them to campus life and to academic work that differs significantly from that engaged in during secondary school. While the focus of seminars may vary, many provide occasions for students to engage in academic discourse, inquiry, and other growth experiences that would provide opportunities for learning scenarios in which students explore notions of trust, expertise, and authority.

\section{Living-and-Learning Communities}

Students join living-and-learning communities in order to engage in activities with students who have similar interests and who may be taking a common suite of classes. This shared sense of purpose and the opportunity to become engaged in a field of interest would provide fertile ground to engage in learning experiences investigating the fractured nature of information. The sense of community provided by this model would provide a safe space for such discussions. The mix of curricular and co-curricular activities is particularly advantageous for an immersive learning opportunity.

\section{Undergraduate Research}

Students who engage in the empirical research process participate in a process that requires necessary and impactful inquiry, research, and engagement in a scholarly conversation. The work involved is immediate and relevant, providing circumstances ideal for the exploration of issues connected to credibility, authority, and expertise, both in connection with the research advisor and with those upon whose work the research rests.

\section{Service Learning or Internships}

Experiential learning provides opportunities for students to connect what they have taken from formal learning situations and apply it to hands-on situations. In many cases, students have a chance to interact with professionals in a field and have the opportunity to reflect on the intersections of formal and experiential learning.

\section{Capstone Courses}

These courses, generally offered as seminars, allow space for the habit of critical reflection that students aren't accustomed to. The intellectual give and take, and the need to base one's contributions on knowledge of the work of scholars in the field, provide a challenging yet supportive community of inquiry. 


\section{Interdisciplinary Courses}

If designed appropriately, these courses would encourage the comparison of different research methods or ways of investigating, providing an opportunity for students to question some of their disciplinary assumptions. Interdisciplinary courses taken early in a student's time in college would challenge habits of accepting authority uncritically that are retained from high school.

\section{Pedagogical Internships}

Increasing numbers of colleges and universities are engaging students as interns to faculty to provide the "student perspective" on the dynamics of a classroom and the teaching and climate of inquiry within it. This kind of experience draws students into the circle of increasing expertise, discourse of the discipline, and habits of mind needed to understand how the academy itself functions and how academic inquiry works. Such learning opportunities for students also create conditions for developing simultaneous trust in an authority and the safe space to question the authority of an expert-the faculty member. For the faculty member, receiving sustained feedback on teaching abilities with challenging content from a student affords opportunities for professional growth and the cultivation of a community of inquiry where trust can grow.

\section{MIND-SET AND METALITERACY IN AN EVOLVING INFORMATION ENVIRONMENT}

The venues described in the previous section allow learners to engage in rich, meaningful conversations with fellow students and with subject or professional experts who are modeling the spirit of inquiry. These types of engagements have the potential to build the atmosphere of trust that is needed to analyze issues related to authority, expertise, and credibility.

These transformative learning experiences require challenging one's own mind-set to recognize the need to confront, and then effectively and consistently grapple with, one's own biases, predilictions, and world views. It is particularly hard to do so today, when much of the information one encounters has been presented from within a filter bubble that mirrors one's own convictions. Listening closely to the understandings of others, sharing one's own thoughts, learning more through research and inquiry, and then reexamining initial knowledge and assumptions are vital accomplishments for college students. The information environment changes continuously, though underlying issues that impact how one finds and uses information-such as confirmation bias-do not. Learning opportunities that allow for deep engagement with others move beyond cognitive and behavioral goals to address the metacognitive and affective issues. The metaliteracy framework highlights the importance of integrating these four learning domainscognitive, behavioral, affective, and metacognitive-and aligns with transformative learning:

The use of the term metaliteracy suggests a way of thinking about one's own literacy. To be metaliterate requires individuals to understand their existing literacy strengths and areas for improvement and make decisions about their learning. The ability to critically self-assess different competencies and to recognize one's need for intgrated literacies in today's information environment is a metaliteracy. ${ }^{27}$

Metaliteracy also emphasizes the role of learner as creator, as well as the collaborative nature of information creation. Technology provides unlimited opportunities for creating and sharing information, both individually and with others. When developing shareable information, working with others, both locally and globally, has the capacity to encourage discussion and reflection that includes issues of trust, authority, credibility, and expertise.

\section{DESIGNING FRAMEWORK TEACHING FOR MAXIMUM IMPACT}

It is significant that there are multiple points of overlap between the Association of College and Research Libraries' (ACRL) Framework for Information Literacy for Higher Education, which was informed by metaliteracy, and the theory of transformative learning. ${ }^{28}$ The ACRL Framework also foregrounds habits of mind, builds on the idea of thresholds that students need to traverse on their way to new understandings, and stresses the lifelong nature of information literacy.

The pertinent knowledge practices and dispostions found within the six frames-but particularly "Authority Is Constructed and Contextual," "Research as Inquiry," and "Scholarship as Conversation"- - may be used within the learning venues to consider issues of trust, authority, credibility, and expertise. To address knowledge practices and dispositions in a programmatic way throughout the venues, one method for charting them is to use a calibrated approach in which the practices (and matching dispositions, where appropriate) are introduced in the way that makes sense for the curricular or co-curricular context, then are built on progressively in other venues.

For example, in the "Research as Inquiry" frame, one knowledge practice central to inquiry is "formulate questions for research based on information gaps or on reexamination of existing, possibly conflicting, information." For this same frame, a disposition-an affective or attitudinal driver-is "maintain an open mind and a critical stance." The pairing of the knowledge practice with the disposition in this case creates a more powerful learning goal for the student: "develop research questions that require ongoing reflection, open-mindedness, and sustained attention to 


\section{FEATURE}

conflicting information." The combinations of knowledge practices and dispositions through rewriting and recasting reach toward the "habits of mind" needed for students to experience the necessary ambiguity of the highly mutable, uncertain, and fragmented information environment of the present. Repeated experiences with these cogent combinations of knowledge practices and dispositions, designed into learning venues, provide students with safe but challenging ways to test their assumptions, reflect on their own deficits in knowledge, address some of their cognitive biases, and develop the emotional "muscle" to deal with ambiguity and the polarization they see swirling around them.

A calibrated approach to writing learning goals for various venues described in this article suggests myriad possibilities for librarians and disciplinary faculty to collaborate on course and learning design. The flexibility inherent in this instructional design method permits cross-frame matchings that may be appropriate for a particular learning goal. It is also possible that a goal is well suited to a second knowedge practice or disposition. Both of these cases are to be found in the third example below; however, care should be taken so that the learning experience remains focused and the goal achievable, which suggests restraint in the selection process.

Below are three suggested examples of knowledge practice, disposition, and learning goal groupings matched with potential venues for their use and assignments that would help to reach these programmatic goals (learning outcomes would be created for specific situations). Please note that while the knowledge practices and dispositions are taken directly from the Framework, the learning goals are not. They have been written to meet a specific learning need and situations in which that learning might take place. The first example uses the pairing and learning goal that provided context above and links it to two potential learning experiences.

\section{RESEARCH AS INQUIRY}

Knowledge Practice: Formulate questions for research based on information gaps or on reexamination of existing, possibly conflicting, information.

Disposition: Maintain an open mind and a critical stance.

Learning Goal: Develop research questions that require ongoing reflection, open-mindedness, and sustained attention to conflicting information.

With the "Research as Inquiry" learning goal created above from the knowledge practice and disposition, general learning goals in two venues might be as follows:

\section{First-Year Writing Course}

Students develop one research question on the topic of sustainability that they investigate through inquiry into three different information sources with different perspectives and resolutions of possible conflicts according to the evidence provided in the sources.

\section{Senior Capstone (Synthesis) Course}

Students create a research proposal with a well-defined research question and two subquestions on the relationship between sustainability and community development, and seek to create a solution for a local community problem grounded in sustainability.

\section{AUTHORITY IS CONSTRUCTED AND CONTEXTUAL}

Another example of calibration is designed to deepen habits of mind.

Knowledge Practice: Students understand the increasingly social nature of the information ecosystem where authorities actively connect with each other and with sources over time.

Disposition: Develop an awareness of the importance of assessing content with a skeptical stance and with selfawareness of their own biases and world views.

Learning Goal: Students identify their own assumptions in evaluating the content produced by different interest groups in a contemporary political debate.

This practice calls on students to see connections among authorities and experts, not just individual sources in isolation. Combining this knowledge practice and this disposition creates a habit of mind that looks for authoritative individuals or groups, and their relationships with each other, while requiring students to suspend their own biases and preconceptions in examining those sources or networks of experts. This particular habit of mind is especially crucial now when experts and authorities may be legitimately questioned, when citizens themselves contribute to the information ecosystem, and when markers of authority are more fluid and uncertain.

A calibrated approach to this learning goal in different venues might be as follows:

\section{Living-and-Learning Community}

Students in a living-and-learning cohort examine immigration through the multiple lenses of culture, economics, workforce development, law, social justice, and international relations. Students identify the conflicting perspectives from different interest groups represented on the current immigration issues in each lens and the place of those perspectives in the media ecosystem, and then identify their own assumptions in evaluating the sources of information represented by those interest groups.

\section{Undergraduate Research}

Students in a junior political issues course conduct research into contemporary immigration issues by developing a research question and examining a range of scholarly 
perspectives before developing a survey instrument concerning attitudes about immigration on their campus and developing a critical reflection journal on their findings both from literature review and local research through the survey administration.

\section{Service Learning or Internship}

Students in a social work class with a community-service requirement take an instrument on implicit bias as precursor to field work in their city or community alongside social work professionals to interview undocumented immigrants on their social and information needs.

\section{SCHOLARSHIP AS CONVERSATION AND AUTHORITY IS CONSTRUCTED AND CONTEXTUAL}

A third example uses two related knowledge practices, one from the "Scholarship as Conversation" ( $\mathrm{SaC}$ ) frame and one from the "Authority Is Constructed and Contextual" frame (AICC). An appropriate disposition is found in "Scholarship as Conversation." This calibration is designed to encourage reflection on one's role as an information creator and the recognition that created information is subject to scrutiny and feedback by others.

Knowledge Practice: Understand the increasingly social nature of the information ecosystem where authorities connect with one another and sources develop over time (AICC).

Knowledge Practice: Contribute to the scholarly conversation at an appropriate level, such as local online community, guided discussion, undergraduate research journal, conference presentation, or poster session $(\mathrm{SaC})$.

Disposition: Understand the responsibility that comes with entering the conversation through participatory channels $(\mathrm{SaC})$.

Learning Goal: Students recognize their responsibilities while participating in a community of practice engaged in generating information.

Learners are often used to creating or sharing content on informal social media sites, but many do not see themselves as contributors to more formal information sites and may not recognize the responsibilities that come with doing so. The following venues would provide opportunities to do so in an atmosphere of inquiry, reflection, and trust. This goal might be calibrated at different levels:

\section{Lower-Level Inquiry-Based Courses}

Students in a gender studies or information literacy course participate in the WikiProject Women in Red and work in teams to research and write entries for women for the project that strive to improve the gender balance on Wikipedia. Teams post their entries and then monitor and assess the changes that others make to their entries.

\section{Senior Capstone Course}

Students in a thematically based senior capstone course create a topical blog for which they write entries referencing the formal and informal writings of scholars and extending the conversation through their own contributions. They might ask these scholars for their feedback through blog contributions.

The examples provided here are not prescriptive or definitive. The calibrations need to be tailored to a particular group of students, level of learning, venue, and course goals, among other elements. They must be well integrated into a course that is designed to foster a community of inquiry in order to accomplish the goals that characterize transformative learning and metaliteracy. A faculty member's collaboration with a librarian might follow the process described here to create learning goals from knowledge practice and disposition pairings, followed by appropriate learning outcomes and assessment methods.

\section{CONCLUSION}

In these times, the challenges for librarians who teach and who partner with faculty and others who teach cannot be met by incremental changes or small adjustments. Difficulties with trust, credibility, authority, and expertise now permeate our society, causing large numbers of citizens to question facts, journalistic integrity, scholarly methods, and what in previous periods in history were accepted as settled facts and reliable information sources, including experts. The fragmentation of the information landscape, the toxicity of much current public discourse, and the attention deficits caused by social media and mobile devices are all both symptoms of the deeper trust problem in our society and causes of further declines in trust. This very large problem pervades our culture, our politics, our communities, and our educational system.

Librarians and libraries can contribute to their institutions most significantly in the future by fostering communities of inquiry that model a discourse of trust-where experts and authorities are questioned and interrogated with respect and with informed skepticism; where those communities of inquiry include colleagues within and beyond the library, as well as community members and alumni; and where students themselves join those communities and grapple with big challenges and the confusing welter of the scholarly information landscape in appropriately calibrated ways. Librarians should focus on the high-impact practices that immerse students in deep and self-regulated learning and that cause them to question their assumptions in a safe environment. Such high-impact practices should begin in the first year and continue in developmentally appropriate ways throughout the undergraduate years, and librarians should position their own expertise and co-design high-impact 


\section{FEATURE}

learning experiences with faculty and, when possible, with students themselves. Students will develop habits of mind to face the unsettling world not through occasional exposure to complexities or through reductive checklists and small outcomes for learning, but through regular and carefully designed experiences with large learning goals that require rigorous thought and critical self-reflection.

The habits of mind that speak to the best in all of us as members of academic and larger communities-curiosity and intellectual engagement, empathetic and respectful listening, a driving search for facts and truth grounded in reality, a willingness to suspend judgement and to remain open to new information and perspectives, and an acceptance of our own fallibility and blind spots, with the motivation to correct them-should be the same habits of mind that we cultivate in our students. They are our future, and the highest professional responsibility we can perform is trusting them to become members of the academic community rather than passive observers of it or consumers of its credentials. All of us-librarians, faculty members, staff, and administratorscan join in this large quest for restoring trust by engaging students in that search. The habits of mind that build trust, developed in larger communities of inquiry and stretching across our campuses, among campuses, into communities, and even into other countries, are one of our best hopes for shaping a more civilized society.

\section{References}

1. "A Wider Ideological Gap Between More and Less Educated Adults," Pew Research Center for the People and the Press (blog), April 26, 2016, http://www.people-press.org/2016/04/26/a-wider -ideological-gap-between-more-and-less-educated-adults/.

2. Rob Faris et al., "Partisanship, Propaganda, and Disinformation: Online Media and the 2016 U.S. Presidential Election," Berkman Klein Center for Internet and Society at Harvard University, August 16, 2017, https://cyber.harvard.edu/publications /2017/08/mediacloud.

3. Sam Wineburg et al., "Evaluating Information: The Cornerstone of Civic Online Reasoning," Stanford Digital Repository, November 22, 2016, https://purl.stanford.edu/fv75lyt5934.

4. "Posts from the 'Digital Polarization Initiative' Category," AASCU's American Democracy Project, accessed November 21, 2017, https://adpaascu.wordpress.com/category/digital-polarization -initiative/.

5. Brad Love, Michael Mackert, and Kami Silk, "Consumer Trust in Information Sources: Testing an Interdisciplinary Model," SAGE Open 3, no. 2 (April 15, 2013): 1, https://doi.org $/ 10.1177 / 2158244013492782$

6. Ibid., 2 .

7. Shawn Tseng and B. J. Fogg, "Credibility and Computing Technology," Communications of the ACM 42, no. 5 (May 1999): 40, https://doi.org/10.1145/301353.301402.

8. Ibid.

9. Julian Sanchez, "Epistemic Closure, Technology, and the End of Distance," Julian Sanchez (blog), April 7, 2010, http://www .juliansanchez.com/2010/04/07/epistemic-closure-technology -nd-the-end-of-distance/.

10. Eli Pariser, The Filter Bubble: What the Internet Is Hiding from You (New York: Penguin Press, 2011).
11. Levi Boxwell, Matthew Gentzkow, and Jesse M. Shapiro, "Is the Internet Causing Political Polarization? Evidence from Demographics," Brown University, March 2017, https://www.brown .edu/Research/Shapiro/pdfs/age-polars.pdf.

12. Jacob Silverman, Terms of Service: Social Media and the Price of Constant Connection (New York: Harper, 2015); Adam Alter, Irresistible: The Rise of Addictive Technology and the Business of Keeping Us Hooked (New York: Penguin Press, 2017).

13. Tom Nichols, The Death of Expertise: The Campaign against Established Knowledge and Why It Matters (New York: Oxford University Press, 2017).

14. See the following for overviews of the reproducibility crisis: https://theconversation.com/the-science-reproducibility-crisisand-what-can-be-done-about-it-74198; https://fivethirtyeight .com/features/failure-is-moving-science-forward/; https://www .chronicle.com/article/A-New-Theory-on-How/240470; https:// www.insidehighered.com/blogs/rethinking-research/how-better -training-can-help-fix-research-reproducibility-crisis.

15. Yuval Levin, The Fractured Republic: Renewing America's Social Contract in the Age of Individualism (New York: Basic Books, 2016)

16. Daniel Kahneman, Thinking, Fast and Slow (New York: Farrar Straus and Giroux, 2011).

17. Charity Johansson and Peter Felten, Transforming Students: Fulfilling the Promise of Higher Education (Baltimore: John Hopkins University Press, 2014), 3.

18. Jack Mezirow, "Transformative Learning as Discourse," Journal of Transformative Education 1, no. 1 (January 2003): 58, https:// doi.org/10.1177/1541344603252172

19. George D. Kuh and Carol Geary Schneider, High-Impact Educational Practices: What They Are, Who Has Access to Them, and Why They Matter (Washington, DC: Association of American Colleges and Universities, 2008).

20. Matthew Wawrzynski and Roger Baldwin, "Promoting HighImpact Student Learning: Connecting Key Components of the Collegiate Experience," New Directions for Higher Education 2014, no. 165 (March 2014): 51-62, https://doi.org/10.1002/he.20083.

21. Mezirow, "Transformative Learning as Discourse."

22. Stephen Brookfield, "Critical Reflection as an Adult Learning Process," in Handbook of Reflection and Reflective Inquiry, ed. Nona Lyons (Boston: Springer US, 2010), 215-36, https://doi .org/10.1007/978-0-387-85744-2_11.

23. "College Learning for the New Global Century: A Report from the National Leadership Council for Liberal Education \& America's Promise" (Washington, DC: Association of American Colleges and Universities, 2007), 38, https://www.aacu.org/sites /default/files/files/LEAP/GlobalCentury_final.pdf.

24. Jayne E. Brownell and Lynn E. Swaner, "High-Impact Practices: Applying the Learning Outcomes Literature to the Development of Successful Campus Programs," Peer Review 11, no. 2 (Spring 2009), https://www.aacu.org/publications-research/periodicals /high-impact-practices-applying-learning-outcomes-literature.

25. George D. Kuh, "High-Impact Educational Practices: A Brief Overview," Association of American Colleges and Universities, n.d., http://www.aacu.org/leap/hips.

26. "What Is WCI?," University at Albany, 2017, http://www.albany .edu/wci/about-wci.php.

27. Thomas Mackey and Trudi E. Jacobson, Metaliteracy: Reinventing Information to Empower Learners (Chicago: Neal-Schuman, 2014), 2.

28. Framework for Information Literacy for Higher Education, Association of College and Research Libraries, filed by the ACRL board February 2, 2015, adopted by the ACRL board January 11, 2016 http://www.ala.org/acrl/standards/ilframework. 